\title{
ERRATA
}

\section{A TLR7 agonist enhances the antitumor efficacy of obinutuzumab in murine lymphoma models via NK cells and CD4 T cells}

EJ Cheadle, G Lipowska-Bhalla, SJ Dovedi, E Fagnano, C Klein, J Honeychurch and TM Illidge

Leukemia (2017) 31, 2278; doi:10.1038/leu.2017.218; published online 28 July 2017

Correction to: Leukemia (2017) 31, 1611-1621; doi:10.1038/

leu.2016.352; published online 3 January 2017
Following the publication of this article, it was noted that the HTML version contained the wrong AAP date. The correct AAP date is 28 November 2016.

\section{A novel BCMA/CD3 bispecific T-cell engager for the treatment of multiple myeloma induces selective lysis in vitro and in vivo}

S Hipp, Y-T Tai, D Blanset, P Deegen, J Wahl, O Thomas, B Rattel, PJ Adam, KC Anderson and M Friedrich

Leukemia (2017) 31, 2278; doi:10.1038/leu.2017.219; published online 28 July 2017

Correction to: Leukemia (2017) 31, 1743-1751; doi:10.1038/

leu.2016.388; published online 13 January 2017
Following the publication of this article, it was noted that the HTML version contained the wrong AAP date. The correct AAP date is 27 December 2016. 